BENTUK PERTUNJUKAN GURITAN PADA TRADISI PERNIKAHAN DI KOTA PAGARALAM

DedyFirduansyah, AbiKaroma Batubara

EKSISTENSI MUSIK KOLINTANG KAYU DALAM KEHIDUPAN PIKPP DI PT.PURSI PALEMBANG SUMATERA SELATAN

RIO EKA PUTRA

ESTETIKA TARI MELAJU DENGAN MUTU

Rully Rochayati, Treny Hera

KAJIAN SOSIOLOGI TARI KEBAGH DI MASYARAKAT DESA PENGANDONANKOTA PAGAR ALAMRANI CHINTIA SARI

KONTRIBUSI GURU SENI BUDAYA DALAM PENGEMBANGAN KREATIFITAS SISWA PADA PEMBELAJARAN SENI TARI

Naomi Diah Budi Setyaningrum

45

PENERAPAN METODE RESITASI DALAM PEMBELAJARAN NOTASI TARI PADA PROGRAM STUDI PENDIDIKAN SENDRATASIK UNIVERSITAS PGRI PALEMBANG

EfitaElvandari

PENGARUH METODE KERJA KELOMPOK PADA HASIL PEMBELAJARAN TARI TOPENG IRENG DI KELAS VIII SMP NEGERI 15 PALEMBANG

NEMI KAROLINA

PENGARUH MUSIK DANGDUTTERHADAP KECERDASAN EMOSI REMAJA SMPKELAS IX

NOVDALY FILLAMENTA

SITI RAFIAH SEBAGAI TOKOH PEREMPUAN PENGEMBAN PERISTIWA DALAM SYAIR ABDUL MULUK KARYA RAJA ALI HAJI

MOHAMMAD ARFANI

STRUKTUR KERUANGAN TARI REJANG RENTENG DALAM UPACARA PERSEMBAHYANGAN DI PURA PUSEH DESA KALIREJO KECAMATAN BELITANG II KABUPATEN OKU TIMUR

IWAYAN AYUNITA 


\title{
PENERAPAN METODE RESITASI DALAM PEMBELAJARAN NOTASI TARI PADA PROGRAM STUDI PENDIDIKAN SENDRATASIK UNIVERSITAS PGRI PALEMBANG
}

\author{
Oleh: \\ Efita Elvandari \\ (Dosen FKIP Program Studi Pendidikan Sendratasik Universitas PGRI Palembang)
}

\begin{abstract}
ABSTRAK
Notasi Laban merupakan suatu sistem pencatatan tari yang terstandarisasi guna mencatat dan menganalisis beragam gerak manusia.Penemu aslinya adalah seorang tokoh penting dalam dunia tari modern di Eropa, Rudolf Von Laban.Rudolf von Laban lahir di Bratislava pada tanggal 15 Desember 1879. Berkaitan dengan notasi Laban sebagai sistem pencatatan tari, dalam materi pembelajaran Notasi Tari di program studi pendidikan seni drama, tari, dan musik (sendratasik) universitas PGRI Palembang, notasi Laban juga merupakan materi pokok yang diajarkan kepada mahasiswa semester $\mathrm{VI}$ yang mengambil jurusan/minat seni tari. Dalam proses pembelajaran Notasi Tari ini, mahasiswa diperkenalkan dengan notasi Laban sebagai bahan perkuliahan Notasi Tari. Tujuan penelitian ini adalah untuk mengetahui hasil penerapan metode Resitasi dalam pembelajaran Notasi Tari terhadap mahasiswa semester VI minat tari. Metode yang digunakan adalah metode kuantitatif eksperimen jenis pre-experimental design, yaitu one group pretest-posttest design, menggunakan 30 mahasiswa sebagai sampel, yang diambil dengan teknik sampling random ( acak), dari 2 kelas yang berbeda.
\end{abstract}

Kata Kunci: metode resitasi, pembelajaran notasi tari.

\section{A. PENDAHULUAN}

Notasi Laban sebagai sistem pencatatan tari, dalam materi pembelajaran notasi tari di program studi pendidikan seni drama, tari, dan musik (sendratasik) universitas PGRI Palembang, merupakan materi pokok yang diajarkan kepada mahasiswa semester VI yang mengambil jurusan/minat seni tari. Dalam proses pembelajaran notasi tari ini, mahasiswa diperkenalkan dengan notasi Laban sebagai bahan perkuliahan notasi tari. Mengingat keterbatasan waktu dalam perkuliahan notasi tari (ditempuh dalam 1 semester), maka materi notasi Laban yang diberikan kepada mahasiswa hanya sebatas pada pengetahuan dan pemahaman dari bagian-bagian notasi Laban, pengetahuan dan pemahaman bentuk/gambar simbol/notasi gerak, termasuk variasi-variasi arah, posisi dan level gerak, notasi untuk gerak-gerak pokok, yang meliputi gerak/posisi kaki, gerak/posisi tangan, serta gerak/posisi gabungan antara tangan dan kaki. Pada akhir perkuliahan notasi tari ini, diharapkan mahasiswa dapat membuat notasi/simbol gerak tari, sekaligus dapat mempraktikkan gerak-gerak berdasarkan notasi/simbol yang ada.

Permasalahan yang dijumpai dalam pembelajaran Notasi Tari ini adalah masih banyaknya mahasiswa yang kurang aktif dalam memahami maupun mempelajari bentukbentuk notasi Laban, penempatan notasi utama dan notasi bantu, maupun level. Berdasarkan persepsi penulis, hal ini dikarenakan mahasiswa kurang termotivasi untuk menghafal 
atau sekedar mengingat bentuk-bentuk atau simbol notasi Laban, dengan segala unsur yang melekat seperti arahnya, penempatannya serta levelnya.Dengan kondisi seperti, penulis berinisiatif untuk memberikan semacam penugasan individu untuk memacu mahasiswa agar tergerak untuk meningkatkan pemahaman mereka terhadap notasi Laban, dimana dari hasil penugasan itu diharapkan dapat meningkatkan motivasi mahasiswa baik dalam pemahaman secara teori maupun secara praktik.Tugas-tugas tersebut berbentuk pemahaman secara teori yaitu mengubah deskripsi gerak ke dalam bentuk notasi Laban, dan pemahaman secara praktik yaitu membaca notasi Laban kemudian dipraktikkan sesuai dengan simbol yang dibaca mahasiswa.Penulis memilih metode Resitasi karena dianggap sesuai dengan sistem pembelajaran Notasi Tari.

Metode Resitasi adalah metode penyajian bahan dimana guru memberikan tugas tertentu agar peserta didik melakukan kegiatan belajar. (Syaiful dan Aswin, 2006:85). Metode ini diberikan karena dirasakan materi pembelajaran terlalu banyak sementara waktunya terbatas. Metode Resitasi merupakan cara penyajian bahan pelajaran dimana guru memnerikan seperangkat tugas yang harus dikerjakan peserta didik, baik secara individual maupun secara kelompok. (Mulyasa, 2007:113). Tujuan dari metode Resitasi ini adalah agar merangsang peserta didik untuk aktif belajar baik secara individual maupun secara kelompok. Beberapa tujuan penggunaan metode Resitasi diantaranya: 1) peserta didik memiliki hasil belajar lebih mantap, 2) peserta didik memeperoleh dan memperkaya pengetahuan, serta keterampilan, 3) peserta didik aktif belajar dengan melaksanakan tugas dari pengajar (Roestiyah, 2008:133). Dengan penerapan metode Resitasi diharapkan mahasiswa dapat belajar lebih intensif, karena tugas-tugas yang diberikan membutuhkan pertanggungjawaban dari masing-masing mahasiswa.

\section{B. METODE PENELITIAN}

"Metode penelitian pada dasarnya merupakan cara ilmiah untuk mendapatkan data dengan tujuan dan kegunaan tertentu" (Sugiyono, 2011:2). Dalam penelitian ini, penulis menggunakan metode eksperimen. "Metode penelitian eksperimen dapat diartikan sebagai metode penelitian yang digunakan untuk mencari pengaruh perlakuan tertentu terhadap yang lain dalam kondisi yang terkendalikan" (Sugiyono, 2011:72).

Dalam penelitian ini, penulis menggunakan Pre-Experimental Design yaitu One-Group Pretest-Posttest Design. Menurut Sugiyono (2011:109), "dikatakan PreExperimental Designs, karena desain ini belum merupakan eksperimen sungguh-sungguh, karena masih terdapat variabel luar yang ikut berpengaruh terhadap terbentuknya variabel dependen." Jadi hasil eksperimen yang merupakan variabel dependen itu bukan 
semata-mata dipengaruhi oleh variabel dependen.Hal ini dapat terjadi, karena tidak adanya variabel kontrol, dan sampel tidak dipilih secara random.One-Group PretestPosttest Designs merupakan desain yang terdapat pretest sebelum diberi perlakuan.Dengan demikian perlakuan dapat diketahui lebih akurat, karena dapat membandingkatkan dengan keadaan sebelum diberi perlakuan. Sugiyono (2011 :39-41). Desain ini dapat gigambarkan sebagai berikut:

\section{$\mathrm{O}_{1} \times \mathrm{O}_{2}$}

Keterangan:

$\mathrm{O}_{1}$ : nilai Pretest (sebelum diberi perlakuan)

$\mathrm{x}$ : Perlakuan

$\mathrm{O}_{2}$ : nilai Posttest (sesudah diberi perlakuan)

Dalam penelitian ini hanya ada satu kelompok sampel yang menjadi kelas eksperimen yang dilaksanakan tanpa ada kelas pembanding (kelas kontrol), dimana penelitian bertujuan untuk menerapkan suatu tindakan atau perlakuan agar hasilnya lebih optimal.

\section{Hipotesis dan Kriteria Pengujian Hipotesis}

Hipotesis merupakan jawaban
sementara terhadap rumusan masalah
penelitian, dimana rumusan maslah penelitian
telah dinyatakan dalam bentuk kalimat
pertanyaan.Hipotesis juga dapat dinyatakan

sebagai jawaban teoritis terhadap rumusan masalah penelitian, belum jawaban yang empirik dengan data (Sugiyono, 2011:96).Berdasarkan pendapat tersebut, yang menjadi hipotesis dalam penelitian ini adalah penerapan metode resitasi dapat meningkatkan hasil belajar Notasi Tari pada program studi pendidikan sendratasik universitas PGRI Palembang T.A. 2018-2019. Kriteria pengujian hipotesis adalah sebagai berikut:

1. $\mathrm{Ha}$ : Penerapan metode resitasi dapat meningkatkan hasil belajar Notasi Tari pada program studi pendidikan sendratasik universitas PGRI Palembang T.A. 2018-2019

2. Ho : Penerapan metode resitasi tidak dapat meningkatkan hasil belajar Notasi Tari pada program studi pendidikan sendratasik universitas PGRI Palembang T.A. 2018-2019

Kriteria Pengujian hipotesis dalam penelitian ini adalah:

Ho diterima jika thitung $\leq t_{\text {tabel }}$ berarti Ha ditolak.

Ha diterima jika thitung $\geq t_{\text {tabel }}$ berarti Ho ditolak.

Pada penelitian ini, hipotesis diuji dengan $d k=30(30-1)=29$, dan tabel $=2,045$ dengan taraf signifikansi 0,05 (Sugiyono, 2011:332).

\section{HASIL DAN PEMBAHASAN}

Penelitian ini membahas penerapan metode Resitasi dalam pembelajaran notasi tari pada program studi pendidikan sendratasik, semester VI minat Tari, semester genap 20182019. Materi Yang dipelajari meliputi langkah 
kaki, dan variasinya, pengulangan, lompatan, HOLD,PIN,putaran, titik sentuh kaki dengan lantai, angkatan kaki, angkatan tangan. Metode Resitasi merupakan cara penyajian bahan pelajaran dimana guru memnerikan seperangkat tugas yang harus dikerjakan peserta didik, baik secara individual maupun secara kelompok. (Mulyasa, 2007:113). Tujuan dari metode Resitasi ini adalah agar merangsang peserta didik untuk aktif belajar baik secara individual maupun secara kelompok. Adapun kelebihan dan kekurangan dari metode Resitasii (Syaiful dan Aswin, 2006:78), adalah:

\section{Kelebihan metode Resitasi:}

a. Lebih merangsang peserta didik dalam melakukan aktivitas belajar individual maupun kelompok

b. Dapat mengembangkan kemandirian peserta didik di luar pengawasan guru

c. Dapat membina tanggung jawab dan disiplin peserta didik

d. Dapat mengembangkan kreativitas peserta didik

\section{Kekurangan metode Resitasi:}

a. Peserta didik sulit dikontrol, apa benar ia mengerjakan tugas atau orang lain

b. khusus untuk tugas kelompok, tidak jarang yang mengerjakannya dan menyelesaikannya adalah anak tertentu saja, sedangkan anggota lainnya tidak berpartisipasi dengan baik.

c. Tidak mudah memberikan tugas yang sama sesuai dengan perbedaan individu peserta didik d. Sering memberikan tugas yang monoton dan tidak bervariasi dapat menimbulkan kebosanan peserta didik

Langkah-langkah metode Resitasi (Syaiful dan Aswin, 2006:86), yaitu:

1. Fase pemberian tugas, berkaitan dengan:

a. Tujuan yang akan dicapai

b. Jenis tugas

c. Kemampuan peserta didik

d. Sumber belajar

e. Alokasi waktu untuk mengerjakan tugas

2. Fase pelaksanaan tugas, berkaitan dengan:

a. Pembimbingan pengajar

b. Motivasi dari pengajar

c. Keaktifan peserta didik mengerjakan tugas

d. Mencatat hasil tugas secara sistematis

3. Fase pertanggungjawaban, berkaitan dengan:

a. Hasil penugasan, baik secara lisan maupun tertulis

b. Adanya diskusi tentang hasil penugasan

c. Penilaian hasil tugas peserta didik

\section{Populasi dan Sampel}

Populasi adalah wilayah generalisasi yang terdiri atas objek/subjek yang mempunyai kualitas dan karakteristik tertentu yang ditetapkan oleh peneliti untuk dipelajari dan kemudian ditarik kesimpulannya (Sugiyono, 2011:117). Populasi dalam penelitian adalah seluruh mahasiswa semester VI minat tari yang berjumlah 2 kelas, yaitu kelas VI C dengan jumlah mahasiswa 36 orang, dan kelas VI D 
dengan jumlah mahasiswa 28 orang. Sampel adalah bagian dari jumlah dan karakteristik yang dimiliki oleh populasi tersebut (Sugiyono, 2011:118). Teknik sampling yang digunakan adalah probability sampling, yaitu teknik pengambilan sampel dengan memberikan peluang yang sama bagi setiap unsur (anggota) populasi untuk dipilih menjadi anggota sampel. Dari teknik probability sampling yang digunakan, dipilih jenis simple random sampling, yaitu pengambilan anggota sampel dari populasiyang dilakukan secara acak tanpa memperhatikan strata yang ada dalam populasi itu. (Sugiyono, 2011:120).Dari pengambilan sampel dari dua kelas, didapatkan jumlah sampel sebanyak 30 orang, terdiri dari 15 orang dari kelas $6 \mathrm{C}$ dan 15 orang dari kelas 6D.

\section{Rancangan Perlakuan}

Penelitian ini telah dilaksanakan sebanyak 5 kali pertemuan dengan rancangan perlakuan sebagai berikut:

1. Pertemuan pertama, penulis menggunakan metode ceramah dan demonstrasi, menjelaskan tentang ruang

lingkup notasi Laban, cara membuat notasi/simbol notasi Laban, cara mempraktikkan dari notasi Laban.

2. Pertemuan kedua, penulis menggunakan metode ceramah dan demonstrasi, mereview materi sebelumnya,

Melanjutkan sub bahasan, dan dilanjutkan pemberian pretest kepada peserta didik.
Pretest ini berupa teori yaitu mengubah deskripsi gerak menjadi notasi Laban serta tes pratik yaitu

membaca notasi Laban dipraktikkan dalam bentuk gerak sesuai notasi yang dibaca peserta didik.

3. Pertemuan ketiga, penulis menggunakan metode ceramah, demonstrasi dan resitasi untuk melanjutkan materi, kemudian memberikan tugas mengubah dari deskripsi gerak ke notasi Laban setelah mendemonstrasikan tambahan materi.

4. Pertemuan keempat, penulis menggunakan metode ceramah, demonstrasi dan resitasi untuk melanjutkan materi, kemudian memberikan tugas mempraktikkan dari notasi Laban ke bentuk gerak sesuai notasi yang dibaca peserta didik setelah mendemonstrasikan tambahan materi.

5. Pertemuan kelima, penulis mengambil nilaiposttest setelah 2 pertemuan sebelumnya diberikan perlakuan berupa penerapan metode Resitasi. Materi posttest sama dengan materi pretest yaitu berupa teori yaitu mengubah deskripsi gerak menjadi notasi Laban serta tes praktik yaitu membaca notasi Laban dipraktikkan dalam bentuk gerak sesuai notasi yang dibaca peserta didik.

\section{Rubrik Penilaian}

Kriteria penilaian dalam pembelajaran Notasi Tari ini terdiri dua jenis; penilaian tes teori dan penilaian tes praktik; selanjutnya, dari 
kedua bentuk tes ini, penilaian akhir diperoleh dari rekapitulasi nilai praktik dan teori.Penilaian tes teori meliputi ketepatan bentuk notasi, ketepatan simbol level, dan penempatan notasi. Adapun rubrik penilainnya dapat diuraikan sebagai berikut::

\begin{tabular}{|c|c|c|c|}
\hline \multicolumn{3}{|c|}{ Kriteria Penilaian } & Skor Maksimal \\
\hline $\begin{array}{c}\text { Ketepatan bentuk } \\
\text { notasi }\end{array}$ & $\begin{array}{c}\text { Ketepatan } \\
\text { simbol level }\end{array}$ & $\begin{array}{c}\text { Penempatan } \\
\text { notasi }\end{array}$ & \\
\hline $10-40$ & $10-30$ & $10-30$ & 100 \\
\hline
\end{tabular}

Keterangan:

1. Ketepatan bentuk notasi:

- ukuran notasi dengan ruang metrum

- bentuk gambar notasi (termasuk proporsi gambar)

2. Ketepatan simbol level:

- kesesuaian level dengan simbolnya (tinggisedang-rendah)

- kejelasan simbol level

3. Penempatan notasi
- ketepatan kolom notasi (notasi utama/notasi bantu)

- proporsi penggunaan kolom penempatan notasi

Penilaian tes praktik meliputi ketepatan hitungan dengan gerak, ketepatan gerak dengan level, ketepatan gerak dengan arah gerak. Adapun rubrik penilainnya dapat diuraikan sebagai berikut::

\begin{tabular}{|c|c|c|c|}
\hline \multicolumn{3}{|c|}{ Kriteria Penilaian } & Skor Maksimal \\
\hline $\begin{array}{c}\text { Ketepatan gerak } \\
\text { hitungan }\end{array}$ & $\begin{array}{c}\text { Ketepatan gerak } \\
\text { dengan level }\end{array}$ & $\begin{array}{c}\text { Ketepatan } \\
\text { gerak dengan } \\
\text { arah gerak }\end{array}$ & \multirow{2}{*}{100} \\
\hline $10-40$ & $10-30$ & $10-30$ & \\
\hline
\end{tabular}

\section{Keterangan:}

1. Ketepatan gerak dengan hitungan:

- hitungan sama dengan gerak dalam simbol notasi
2. Ketepatan gerak dengan level

- gerak sesuai dengan level dalam simbol notasi

3. Ketepatan gerak dengan arah gerak 
- gerak sesuai dengan arah dalam simbol notasi

\section{Analisis Data}

Analisis data dalam peneitian ini berupa uji normalitas dan uji hipotesis.

a. Uji Normalitas, dengan tahapan sebagai berikut:

1. Menentukan Range $(R)$

$$
\mathrm{R}=\mathrm{X}_{\text {maks }}-\mathrm{X}_{\text {min }}
$$

2. Menentukan Banyak Kelas $(K)$

$$
K=1+3,3 \log n
$$

3. Menentukan Panjang Kelas $(P)$

$$
P=\frac{R}{K}
$$

4. Membuat Distribusi Frekuensi

\section{Mencari Rata-rata $(\bar{X})$}

$$
\bar{X}=\frac{\sum \mathrm{f}_{\mathrm{x}_{\mathrm{i}}}}{\sum f_{i}}
$$

\section{Mencari Simpangan Baku}

$$
S^{2}=\frac{\left.n \sum f_{i x_{1}^{2}-\left(\sum f i x i\right.}\right)^{2}}{n(n-1)}
$$

7. Menguji Kenormalan Data Dengan Koefisien Kemiringan (Km), yaitu :

$$
K m=\frac{\bar{x}-M o}{S}
$$

\section{b. Uji Hipotesis}

Teknik analisis data dalam penelitian ini menggunakan teknik uji-t. Teknik ini digunakan untuk melihat peningkatan hasil penerapan metode resitasi terhadap pembelajaran Notasi Tari pada program studi pendidikan sendratasik universitas PGRI Palembang, semestaer genap T.A 2018-2019, sebagai berikut:

$$
t=\frac{\overline{x_{1}}-\overline{x_{2}}}{\sqrt[s]{\frac{1}{n 1}+\frac{1}{n 2}}}
$$

\section{Hasil Penerapan Metode Resitasi}

Penerapan metode resitasi dalam pembelajaran notasi tari pada program studi pendidikan sendratasik unversitas PGRI Palembang, telah dilaksanakan pada bulan Maret-April, dilaksanakan sebanyak 5 kali pertemuan, yaitu tgl 16, 23, 30 April 2019, dan tanggal 2 dan 9 Mei 2019. Penerapan metode resitasi sesuai dengan langkah-lagkah sebagai berikut:

1. Fase pemberian tugas, meliputi pemberian tugas di rumah dilluar jam pembelajaran, dan pemberian tugas di dalam kelas pada saat proses belajar mengajar berlangsung, dengan tujuan supaya peserta didik lebih memahami isi materi pembelajaran yang berupa praktik dan teori, dengan alokasi waktu seminggu untuk mengerjakan tugas yang diberikan pengajar (peneliti).

2. Fase pelaksanaan tugas, meliputi tugas yang dikerjakan di rumah, diserahkan pada pengajar pada pertemuan berikutnya, dan dinilai oleh pengajar; tugas di kelas berupa tugas/soal yang diberikan pengajar dan langsung dikerjakan oleh masing-masing peserta didik sesuai dengan soal masingmasing.

3. Fase pertanggungjawaban, meliputi penilaian dari tugas di rumah dan penilaian pada saat peserta didik mengerjakan tugas di 
kelas, kemudian hasil yang sudah diperoleh dibahas bersama-sama di kelas, dan dicari materi mana saja yang masih belum dipahami oleh peserta didik, kemudian diberikan penjelasan lagi sampai peserta didik mendapatkan pemahaman yang lebih jelas. Berdasarkan hasil penelitian yang telah dilakukan, didapatkan hasil penelitian sebagai berikut:

Data dan analisis hasil pretest, didapatkan hasil sebagai berikut:
a. Rata-rata $(\bar{X}): 38,63$
b. Modus (Mo): 10, 14
c. Simpangan baku (S): 8,58
d. Kemiringan kurva (Km): 3.32

Data dan analisis hasil posttest, didapatkan hasil sebagai berikut:
a. Rata-rata $(\bar{X}): 82,60$
b. Modus (Mo): 86, 49
c. Simpangan baku (S): 68,47
d. Kemiringan kurva (Km): -0,55

Dari data hasil pretest dan posttest, kemudian dicari uji hipotesis (uji t), untuk mengetahui peningkatan hasil belajar dari hasil penerapan metode resitasi dalam pembelajaran Notasi Tari pada program studi pendidikan sendratasik universitas PGRI Palembang semester genap T.A. 2018-2019, dengan hasil sebagai berikut:

$$
t=\frac{\overline{x_{1}}-\overline{x_{2}}}{\sqrt[s]{\frac{1}{n 1}+\frac{1}{n 2}}}
$$

Dari hasil perhitungan data diatas, diperoleh hasil uji-t, yaitu thitung sebesar 2,90; selanjutnya dicari nilai dari tabel. Berdasarkan perhitungan diatas telah diketahui thitung sebesar 2,90 dan tabel sebesar 2.045, setelah dikonsultasikan dengan data distribusi-t dengan taraf signifikan n 0,05, maka dapat disimpulkan hipotesis bahwa penggunaan metode resitasi dalam pembelajaran tari notasi tari, sesuai dengan kriteria pengujian hipotesis bahwa Ha diterima jika thitung $\geq$ ttabel $(2,90 \geq 2.045)$ berarti Ho ditolak.

\section{SIMPULAN}

Berdasarkan hasil penelitian yang telah didapatkan peneliti, dapat disimpulkan beberapa hal sebagai berikut. Penerapan metode resitasi sudah sesuai dengan karakter pembelajaran di kelas, karena mata kuliah notasi tari membutuhkan banyak pemberian tugas sebagai bentuk motivasi untuk siswa agar 'terpaksa' belajar, baik latihan-latihan yang berbentuk teori maupun latihan-latihan yang berbentuk praktik; dimana tugas yang diberikan tidak hanya di kampus, tetapi juga di rumah. Dari penerapan metode resitasi ini diperoleh peningkatan hasil belajar yang signifikan. Hal ini dapat dilihat dari perolehan hasil belajar, dimana pada hasil 
pretest(sebelum diterapkan metode resitasi), rata-rata nilai yang diperoleh sebesar 38,63, dan hasil posttest (setelah diterapkan metode resitasi), rata-rata nilai yang diperoleh sebesar 82,60 . Berdasarkan pengujian hipotesis didapat uji-t dengan hasil $t_{\text {Hitung }}=2,90$ sedangkan $t_{\text {Tabel }}=$ 2,045 dengan dk sebesar 29. Hal ini berarti $t_{\text {Hitung }} \geq$ tTabel $_{\text {atau }} 2,90 \geq 2,045$; sehingga dapat disimpulkan bahwa hipotesis yang menyatakan bahwa penerapan metode resitasi dapat meningkatkan hasil belajar notasi tari pada program studi pendidikan sendratasik semester genap tahun pelajaran 2018/2019 diterima.

\section{DAFTAR PUSTAKA}

Sugiyono. 2011. Metode Penelitian Pendidikan: Pendekatan Kuantitatif, Kualitatif, dan R\&D. Bandung: Alfabeta

Mulyasa, E. 2007.Menjadi Guru Profesional Menciptakan Pembelajaran Kreatif Dan Menyenangkan. Bandung:

PT. Remaja Rosdakarya

Roestiyah. 2008. Strategi Belajar Mengajar. Jakarta: PT. Rineka Cipta

Syaiful Bahri dan Aswin Zain. 2006. Strategi Belajar Mengajar. Jakarta: PT. Rineka Cipta. 
